\title{
Using speed of ageing and "microlives" to communicate the effects of lifetime habits and environment
}

The author of this Christmas Feature has informed us that some of the results for women are incorrect in the table (BMJ 2012;345:e8223, doi:10.1136/bmj.e8223). For each subsequent drink (up to 6), the change in life expectancy (years) should have been -1.1 (not "-0.6") and the change in microlives per day should have been -1 (not " $-1 / 2$ "). For fruit and vegetable intake, the change in life expectancy should have been 2.7 (not "3.8") and the change in microlives per day should have been 3 (not "4").

Cite this as: BMJ 2012;345:e8676

๑ BMJ Publishing Group Ltd 2012 